\title{
An emerging simple and effective approach to increase the productivity of thraustochytrids microbial lipids by regulating glycolysis process and triacylglycerols' decomposition
}

\author{
Wang Ma, Yu-Zhou Wang, Fang-Tong Nong, Fei Du, Ying-Shuang Xu, Peng-Wei Huang and Xiao-Man Sun * (1)
}

\begin{abstract}
Background: The oleaginous microorganism Schizochytrium sp. is widely used in scientific research and commercial lipid production processes. However, low glucose-to-lipid conversion rate (GLCR) and low lipid productivity of Schizochytrium sp. restrict the feasibility of its use.

Results: Orlistat is a lipase inhibitor, which avoids triacylglycerols (TAGs) from hydrolysis by lipase. TAGs are the main storage forms of fatty acids in Schizochytrium sp. In this study, the usage of orlistat increased the GLCR by $21.88 \%$ in the middle stage of fermentation. Whereas the productivity of lipid increased 1.34 times reaching $0.73 \mathrm{~g} / \mathrm{L} / \mathrm{h}$, the saturated fatty acid and polyunsaturated fatty acid yield increased from 21.2 and 39.1 to 34.9 and $48.5 \mathrm{~g} / \mathrm{L}$, respectively, indicating the advantages of using a lipase inhibitor in microbial lipids fermentation. Similarly, the system was also successful in Thraustochytrid Aurantiochytrium. The metabolic regulatory mechanisms stimulated by orlistat in Schizochytrium sp. were further investigated using transcriptomics and metabolomics. The results showed that orlistat redistributed carbon allocation and enhanced the energy supply when inhibiting the TAGs' degradation pathway. Therefore, lipase in Schizochytrium sp. prefers to hydrolyze saturated fatty acid TAGs into the $\beta$-oxidation pathway.

Conclusions: This study provides a simple and effective approach to improve lipid production, and makes us understand the mechanism of lipid accumulation and decomposition in Schizochytrium sp., offering new guidance for the exploitation of oleaginous microorganisms.
\end{abstract}

Keywords: Lipase inhibitor, Schizochytrium sp., Lipid productivity, Glucose-to-lipid conversion rater, Triacylglycerol

\section{Background}

In recent years, microbial lipids have received increased attention as an attractive renewable source for producing nutraceuticals, biodiesel, nutrition lipids, and functional foods [1]. For example, nutritional lipids, such as polyunsaturated fatty acids (PUFAs), which improve clinical outcomes of patients with acute respiratory distress

*Correspondence: xiaomansun@njnu.edu.cn

School of Food Science and Pharmaceutical Engineering, Nanjing Normal University, 2 Xuelin Road, Qixia District, Nanjing, People's Republic of China syndrome and modulate the COVID-19 anti-inflammatory response [2]; biodiesel, which refers to saturated fatty acids (SFAs), are a class of renewable resource chemicals with high hopes of replacing fossil fuel-based products for greener development [3]. Microbial lipids yields from different types of oleaginous microbes range from 20 to $70 \%$ [4]. However, the economic feasibility of microbial lipids production is still uncertain due to high costs, so it is urgent to produce microbial lipids more economically and efficiently.

Schizochytrium sp., belonging to the Thraustochytriaceae family, can accumulate significant amounts of original author(s) and the source, provide a link to the Creative Commons licence, and indicate if changes were made. The images or other third party material in this article are included in the article's Creative Commons licence, unless indicated otherwise in a credit line to the material. If material is not included in the article's Creative Commons licence and your intended use is not permitted by statutory regulation or exceeds the permitted use, you will need to obtain permission directly from the copyright holder. To view a copy of this licence, visit http://creativecommons.org/licenses/by/4.0/. The Creative Commons Public Domain Dedication waiver (http://creativeco mmons.org/publicdomain/zero/1.0/) applies to the data made available in this article, unless otherwise stated in a credit line to the data. 
lipids [5]. However, high substrate costs and low lipid productivity are the biggest challenges facing the largescale production of microbial lipids [6]. Traditionally, many studies have sought to improve the lipid production of the thraustochytrids through the optimization of fermentation processes. According to the related literature reports, lipid production by Aurantiochytrium sp. T66 was significantly enhanced when the cells were subjected to nitrogen limitation [7]. In addition, when the dissolved oxygen level was maintained at 50\% throughout the whole fermentation process, Aurantiochytrium limacinum SR21 produced lipids at $5.75 \mathrm{~g} / \mathrm{L} /$ day [8]. However, the technology has reached a point where lipid productivity cannot be further improved using fermentation optimization alone. Moreover, many studies have only focused on overall lipid production while ignoring the decrease in lipid productivity in the middle and late stages of fermentation, as well as the glucose-to-lipid conversion rate (GLCR). For example, a report investigated the impact that adjusting the $\mathrm{pH}$ with ammonia and citric acid can increase the lipid production of Schizochytrium sp. by $27.5 \%$, but the lipid productivity and GLCR did not improve during the middle stage of fermentation (48-96 h), which may also be the cause of reaching a peak in production [9]. With the rise of synthetic biology, editing the genome of microorganisms to improve lipid production is also an increasingly viable strategy [10]. The expression of Vitreoscilla stercoraria hemoglobin in Aurantiochytrium sp. SK4 showed that the fatty acid content of the engineered strain was $44 \%$ higher than that of the wild type [11]. Furthermore, a recent study showed that the whole polyketide synthase (PKS) pathway from Shewanella japonica was expressed in Aurantiochytrium, resulting in a $26.9 \%$ increase in the lipid yield [12]. Up to date, nine genera of thraustochytrids have been recognized [13], however, efficient gene editing tools suitable for editing thraustochytrids have not been established. Therefore, the search for a simple and effective metabolic flow disturbance strategy has become the recent research priorities.

In recent years, more and more small-molecule drugs were found to disrupt the certain biological systems by targeting specific enzyme proteins or acting as signal molecules, thereby causing specific phenotypes of native producers [14]. These small-molecule drugs that act as activators or inhibitors are called chemical modulators. Many microorganisms that lack genetic engineering tools have benefited from chemical modulators in their lipid production [15]. The biosynthesis of microbial lipids relies on a powerful supply of adenosine triphosphate (ATP), acetyl-CoA, and nicotinamide adenine dinucleotide (NADPH), and the availability of substrates is the key to balance growth and lipid production as these two processes compete with each other [16]. Recently, most chemical modulators have been used to enhance the supply of acetyl-CoA and NADPH. For example, ethanolamine indirectly participates in the synthesis of fatty acids by regulating acetyl-CoA production. In Scenedesmus obliquus, ethanolamine can increase lipid production by $22 \%$, which is considered a potential marker for improving lipid accumulation [17]. The supply of NADPH in the lipid synthesis process of eukaryotic microbial cells is mainly related to NADP-malic enzymes and enzymes in the pentose phosphate pathway. Liu et al. used inositol to strengthen the supply of NADPH by increasing NADP-malic enzyme activity, which resulted in a $13.9 \%$ increase in the lipid content of Schizochytrium sp. SR21 [18]. Nevertheless, most studies only focused on lipid accumulation, but the problem of lipid degradation cannot be ignored. Many studies have confirmed that the restriction of lipase function plays a significant role in promoting the accumulation of triacylglycerols (TAGs) in Schizosaccharomyces pombe, Mucor circinelloides, and Thalassiosira pseudonana [19-21].

Herein, five chemical modulators of metabolic pathways were selected and their effects were studied. Then, our study focused on the effect of lipase inhibitor orlistat on the lipid accumulation in Schizochytrium sp. HX-308. On this basis, we compared the antioxidant capacity of Schizochytrium sp. with or without orlistat by measuring reactive oxygen species (ROS), NADPH and total antioxidant capacity (T-AOC). Finally, the performances were systematically explained through transcriptomic and metabolomic analyses. The results of this study were expected to further our understanding of Schizochytrium sp. and provide new guidance for microbial lipid production.

\section{Results}

\section{Screening chemical modulators and optimization} of fermentation conditions

The effect of five selected chemical modulators on lipid accumulation in Schizochytrium sp. were studied (Additional file 1: Table S1). For the evaluation of their performance, lipid yield, GLCR and fatty acids content were used as indicators. After 3 days of fermentation, the addition of vorasidenib and terbinafine slightly promoted lipid accumulation (37.13 and $37.8 \mathrm{~g} / \mathrm{L}$ vs $37.01 \mathrm{~g} / \mathrm{L}$ ), which is in line with our expectations, but the GLCR did not improve (Fig. 1). Interestingly, the addition of vorasidenib led to an increase in the proportion of PUFAs to $64.58 \%$, in which the proportion of EPA was 1.24 times that of the control, but the addition of terbinafine had a limited effect on fatty acid content. In contrast, the addition of quinoxaline and hexaconazole negatively affected the lipid accumulation and GLCR, but the percentage of 


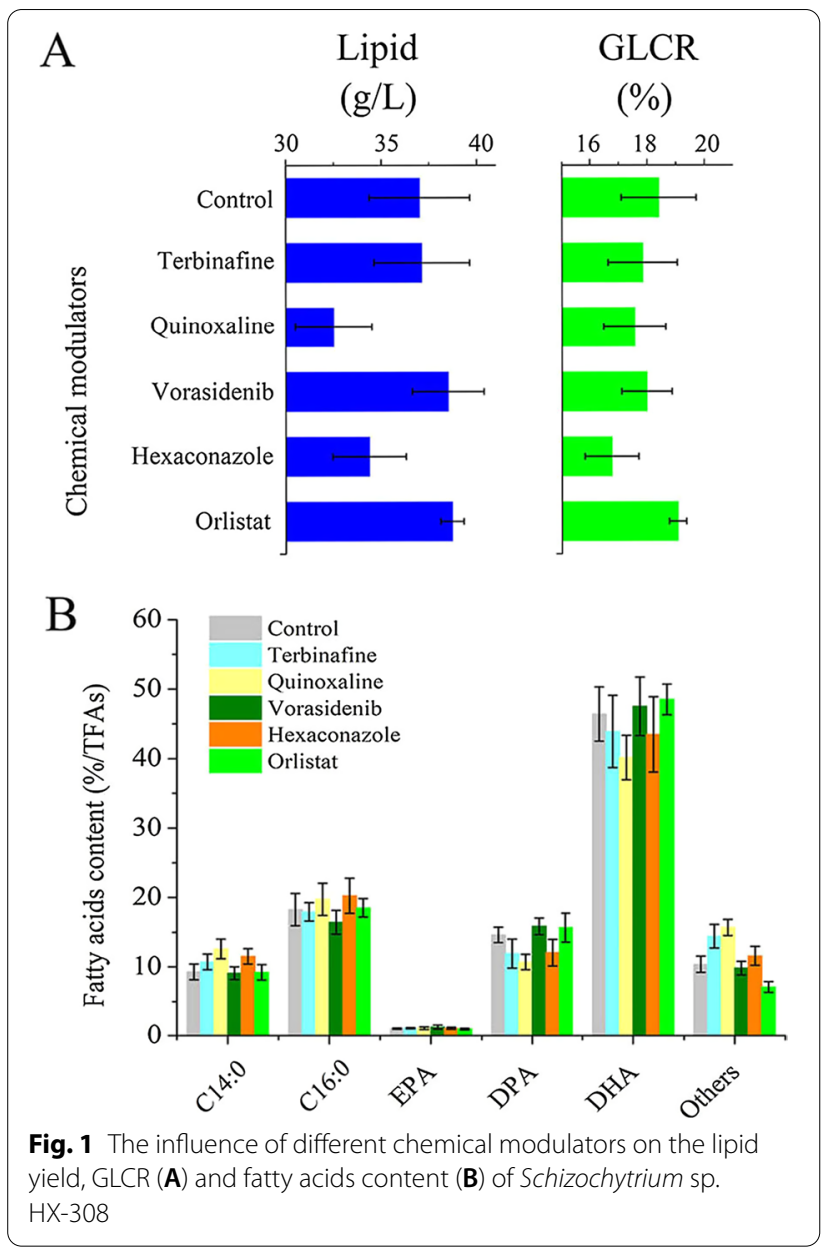

SFAs was increased by $17.32 \%$ and $15.27 \%$, respectively. Unexpectedly, the lipase inhibitor orlistat produced different results: the lipid yield and GLCR were significantly higher than the control, and encouraged Schizochytrium sp. to accumulate more PUFAs (Additional file 1: Fig. S1).

The screening results for the optimal concentration of orlistat are shown in Fig. 2. It was obvious that the lipid production and CDW of Schizochytrium sp. significantly increased with the increase of orlistat concentration $(0-1000 \mathrm{mg} / \mathrm{L})$. After $120 \mathrm{~h}$ of fermentation, $87.89 \mathrm{~g} / \mathrm{L}$ lipid production and $138.83 \mathrm{~g} / \mathrm{L} \mathrm{CDW}$ were obtained at a concentration of $1000 \mathrm{mg} / \mathrm{L}$ orlistat, which were 1.34 and 1.25 times higher than that of the control, respectively. Furthermore, the addition of lipase inhibitors also had a significant impact on the fatty acid composition of Schizochytrium sp. In the concentration range of $0-5 \mathrm{mg} / \mathrm{L}$, the proportion of SFA decreased with an increase in orlistat concentration. Moreover, the proportion of SFA gradually increased when the concentration of orlistat was higher than $5 \mathrm{mg} / \mathrm{L}$, and the proportion of SFA accounted for $39.71 \%$ of the total fatty acids (TFAs) with
$1000 \mathrm{mg} / \mathrm{L}$ orlistat. In addition, the promotion of lipid yield in Schizochytrium sp. gradually decreased when the concentration of orlistat exceeded $100 \mathrm{mg} / \mathrm{L}$ (Fig. 2A). It illustrates that the GLCR increased as the concentration of orlistat increased, and up to $22.69 \%$ at $1000 \mathrm{mg} / \mathrm{L}$ orlistat, which was $9.45 \%$ higher than that of the control. Not surprisingly, the addition of orlistat accelerated the consumption of glucose by Schizochytrium sp., and the total glucose consumption was 1.23 times higher than that of the control when orlistat concentration was $1000 \mathrm{mg} / \mathrm{L}$ (Fig. 2B).

The addition of chemical regulators at different time points may yield different results [22]. Therefore, $0 \mathrm{~h}$ (fermentation start), $12 \mathrm{~h}$ (exponential growth period), $24 \mathrm{~h}$ (late growth period), and $36 \mathrm{~h}$ (rapid lipid accumulation period) were chosen to add the lipase inhibitor with concentrations of $5 \mathrm{mg} / \mathrm{L}$ and $1000 \mathrm{mg} / \mathrm{L}$. After 5 days of fermentation, the addition of orlistat at different stages resulted in different changes in lipid productivity (Fig. 3). In the $5 \mathrm{mg} / \mathrm{L}$ orlistat treatments, adding orlistat at $24 \mathrm{~h}$ yielded $69.24 \mathrm{~g} / \mathrm{L}$ lipid production, which was $5.94 \%$ higher than the control. Additionally, the proportion of PUFAs increased to $68.41 \%$, while that of the control group was only $58.8 \%$ (Additional file 1 : Fig. S2). The lipid yield in the $1000 \mathrm{mg} / \mathrm{L}$ orlistat treatments decreased with the delay in the orlistat supplementation time, and a lipid yield of $87.89 \mathrm{~g} / \mathrm{L}$ was obtained at $0 \mathrm{~h}$, which was $34 \%$ higher than that of the control (Fig. 3A). It was speculated that after low concentrations of orlistat are metabolized by Schizochytrium sp., lipase will have a rapid consumption period of lipids, and adding inhibitors at $24 \mathrm{~h}$ can delay the rapid consumption of lipids to the later stages of fermentation. Recently, Chang et al. found that TAG lipase may be involved in the preferential hydrolysis of SFAs in the process of lipid turnover [23]. The changes in the ratio of fatty acids during the nonfeeding fermentation process also support this conclusion (Additional file 1: Figs. S3, S4), which may explain the experimental phenomenon was observed. Therefore, adding $1000 \mathrm{mg} / \mathrm{L}$ lipase inhibitor at $0 \mathrm{~h}$ improved lipid accumulation, and adding $5 \mathrm{mg} / \mathrm{L}$ lipase inhibitor at $24 \mathrm{~h}$ resulted in a higher proportion of PUFAs.

Figure 3B shows that the addition of orlistat led to a significantly higher consumption of glucose by Schizochytrium sp. than the control. Moreover, as shown in Fig. 3C, the lipid productivity increased with culture time in the three groups, with the $1000 \mathrm{mg} / \mathrm{L}$ orlistat treatment reaching its maximum at $60-72 \mathrm{~h}$, whereas the maximum lipid productivity of the control was at 72-84 h. Compared with the control, the orlistat treatments exhibited an overall higher lipid productivity during the entire fermentation period. Even at the end of fermentation, the lipid productivity reached 


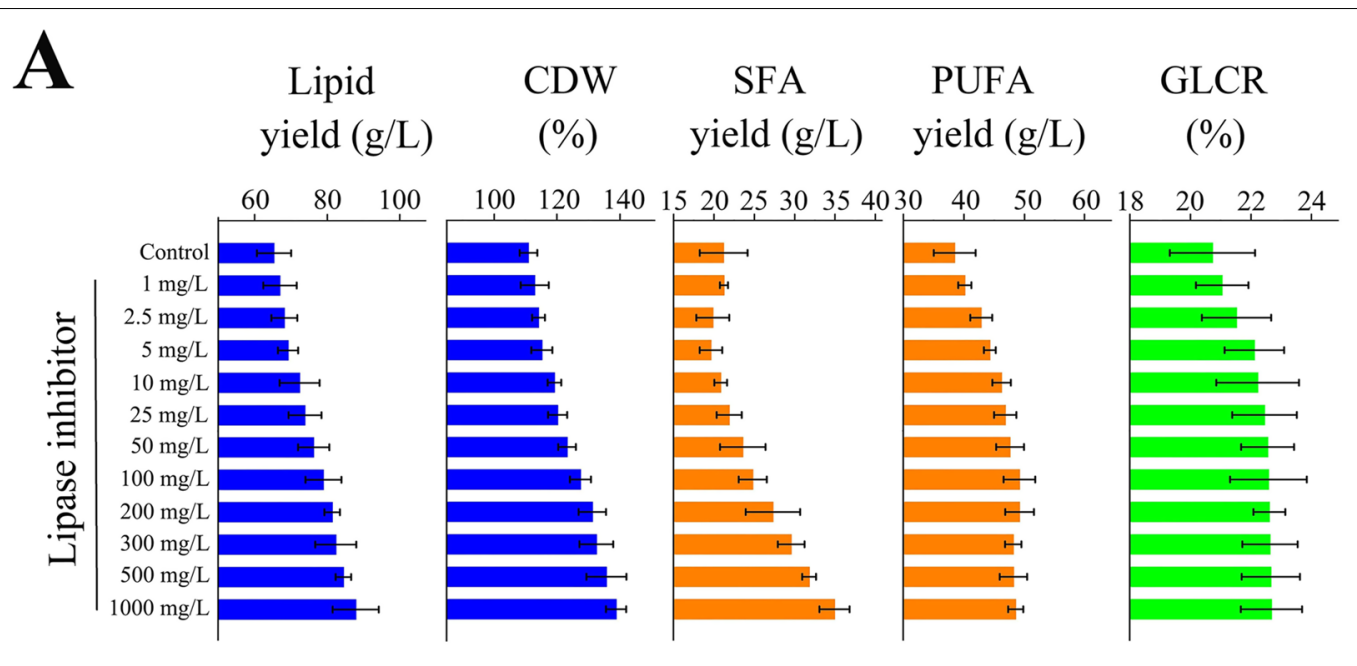

B

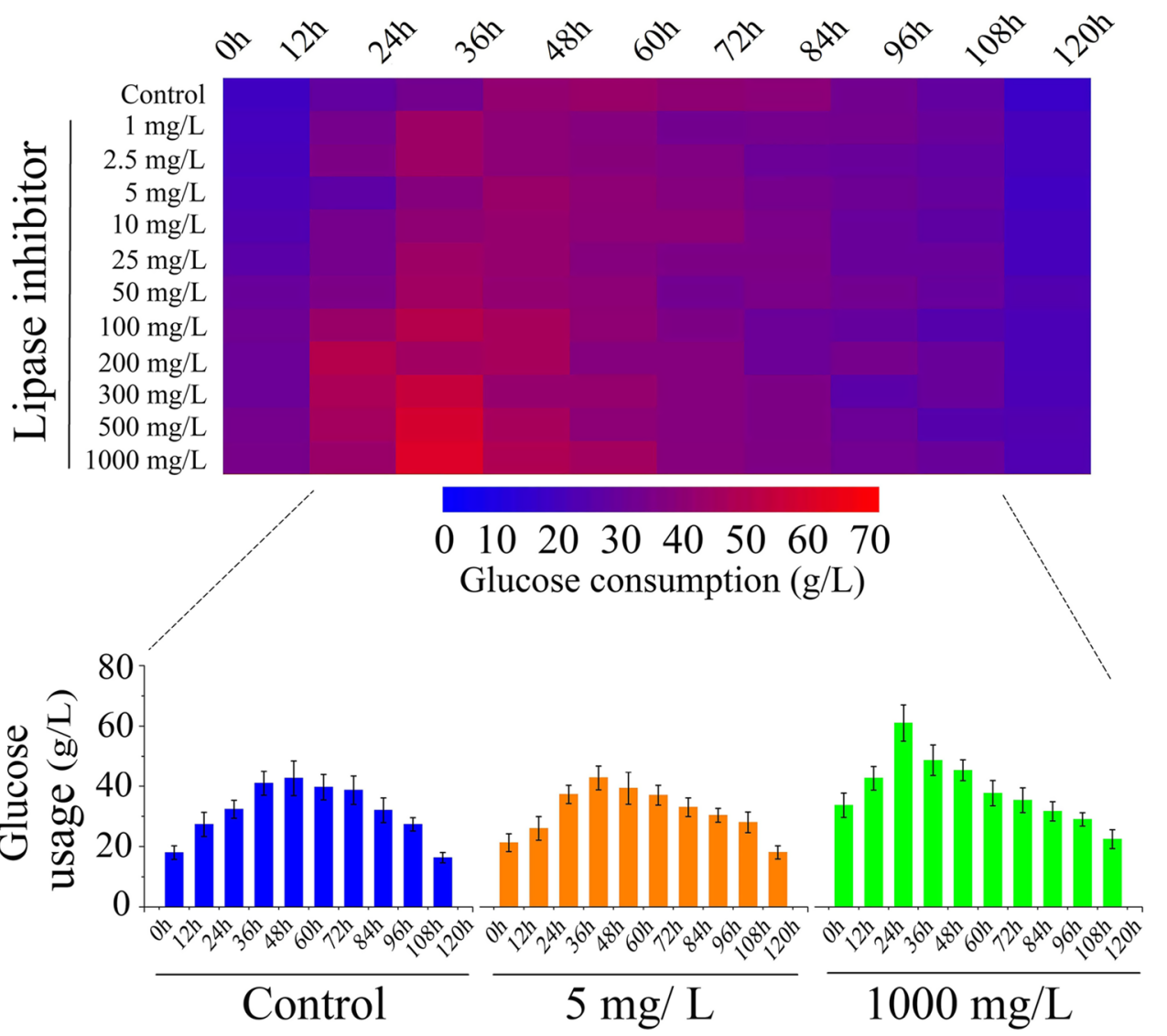

Fig. 2 The effect of different lipase inhibitor concentration on the fermentation of Schizochytrium sp. HX-308. A Changes in Lipid yield, CDW, SFA, PUFA, GLCR and $\mathbf{B}$ glucose consumption under fermentation conditions in the presence of different concentrations of lipase inhibitors

$0.49 \mathrm{~g} / \mathrm{L} / \mathrm{h}$ in the $1000 \mathrm{mg} / \mathrm{L}$ orlistat treatment, which was about 1.3 -fold higher than in the control. In addition, orlistat resulted in a change in GLCR, which increased by $21.88 \%$ compared with the control at a concentration of $1000 \mathrm{mg} / \mathrm{L}$ orlistat in the middle stage of fermentation (60-96 h). In a word, by adding the lipase inhibitor orlistat, the lipid productivity and GLCR of Schizochytrium sp. are improved, which greatly saves the substrate cost and time cost of producing microbial lipids (Table 1). 

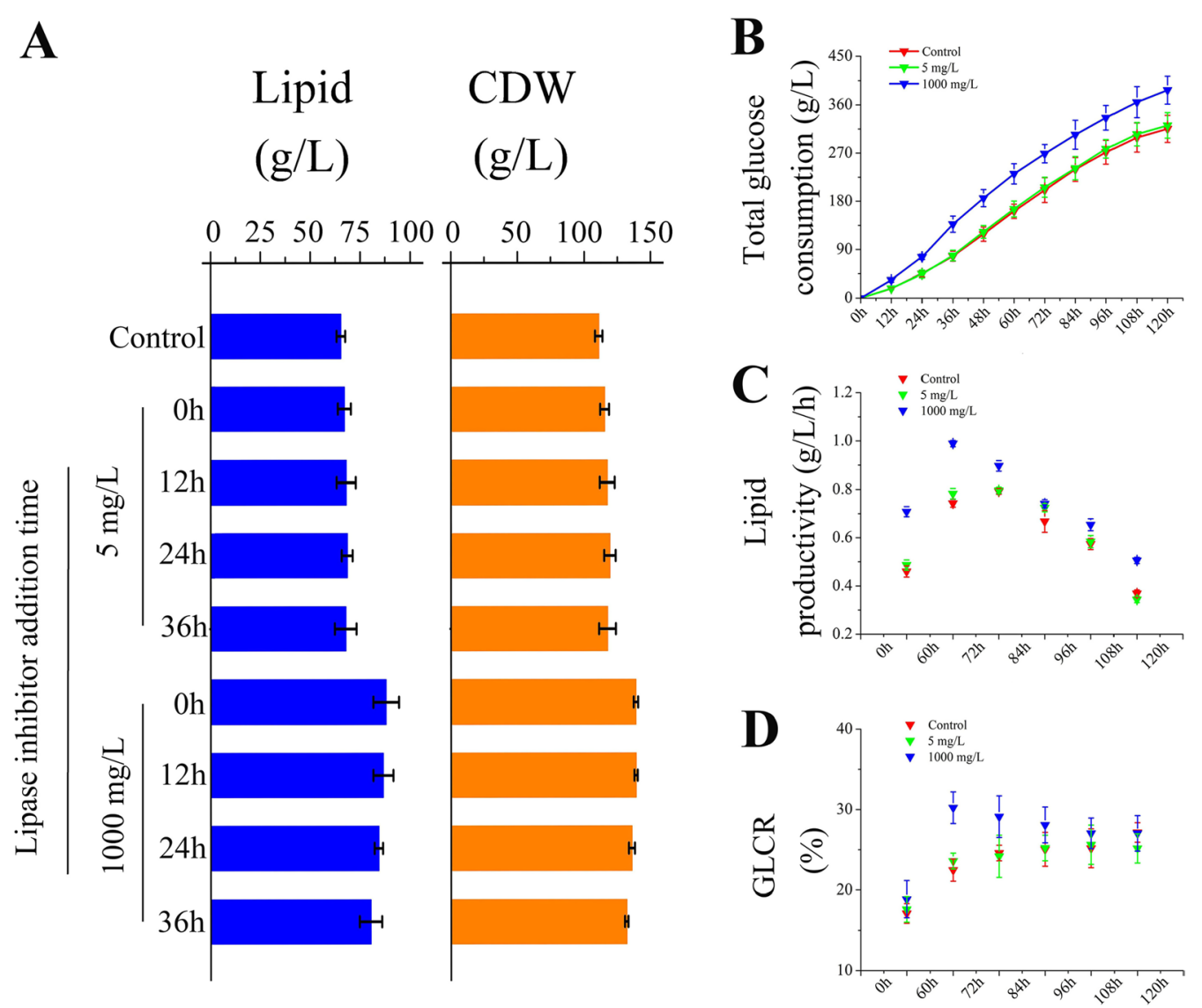

Fig. 3 Effect of 5 mg/L and $1000 \mathrm{mg} / \mathrm{L}$ lipase inhibitor addition time for $\mathbf{A}$ Lipid, CDW and $\mathbf{B}$ total glucose consumption and $\mathbf{C}$ lipid productivity and $\mathbf{D}$ GLCR

Table 1 Some methods to improve the productivity and GLCR of Thraustochytrids

\begin{tabular}{|c|c|c|c|c|}
\hline Strain & Strategy & $\begin{array}{l}\text { Lipid productivity } \\
\text { (g/L/h) }\end{array}$ & GLCR (\%) & References \\
\hline Schizochytrium sp. HX-308 & Adaptive evolution by continuous high oxygen & $0.471 \pm 0.02$ & $14.14 \pm 0.5$ & [24] \\
\hline Schizochytrium sp. HX-308 & Adaptive evolution under high salinity stress & $0.528 \pm 0.03$ & $20.05 \pm 0.4$ & [25] \\
\hline Thraustochytrium sp. T01 & Organic acids/phosphate salt addition & $0.128 \pm 0.01$ & - & [26] \\
\hline Aurantiochytrium sp. SW1 & Kinetin, jasmonic acid, gibberellic acid addition & $0.154 \pm 0.01$ & - & [27] \\
\hline Schizochytrium sp. & Malonate addition & $0.231 \pm 0.02$ & - & [28] \\
\hline Schizochytrium sp. & Ascorbic acid as elicitor & $0.218 \pm 0.02$ & $21.81 \pm 0.4$ & [29] \\
\hline Aurantiochytrium sp. SD116 & Overexpression of G6PDH & $0.055 \pm 0.01$ & $11.01 \pm 0.2$ & {$[30]$} \\
\hline Schizochytrium sp. ATCC20888 & Heterologous overexpression of multiple-genes & $0.112 \pm 0.01$ & $18.75 \pm 0.4$ & [31] \\
\hline Schizochytrium sp. TIO1101 & Overexpression of ACS gene & $0.074 \pm 0.01$ & $22.33 \pm 0.6$ & [32] \\
\hline Schizochytrium sp. HX-308 & Lipase inhibitor addition & $0.733 \pm 0.02$ & $22.69 \pm 0.6$ & This study \\
\hline
\end{tabular}

\section{Effects of lipase inhibitors on cellular antioxidant activity} It was observed that the addition of orlistat caused a significant increase of ROS in Schizochytrium sp. (Fig. 4A). In the $1000 \mathrm{mg} / \mathrm{L}$ orlistat group, the level of ROS in the cells of the $24 \mathrm{~h}$ was 6.1 times that of the control, and at
24-96 h, the ROS in the $1000 \mathrm{mg} / \mathrm{L}$ orlistat group was much higher than that of the control. When $5 \mathrm{mg} / \mathrm{L}$ orlistat was added after $24 \mathrm{~h}$ of fermentation, the ROS increased significantly at $48 \mathrm{~h}$, reaching 3.3 times that of the control group, and then dropped rapidly. The 

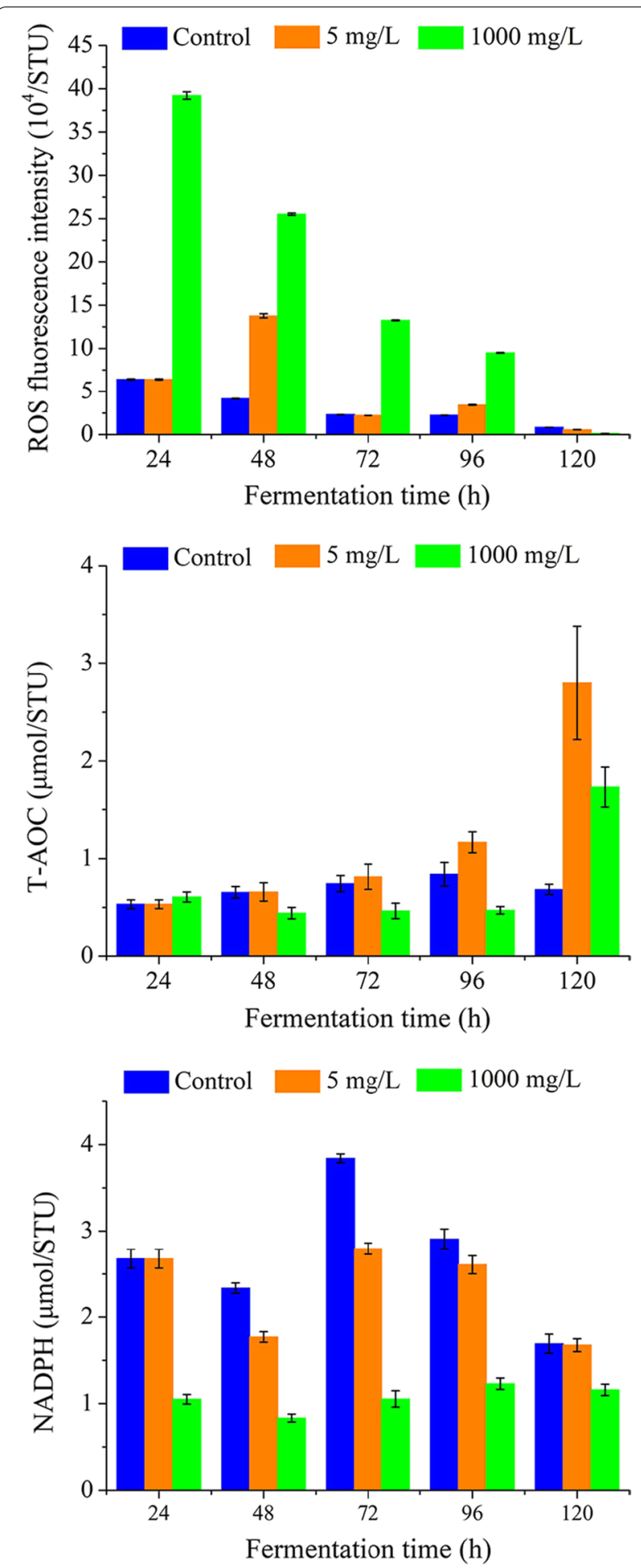

Fig. 4 Comparison of the ROS, T-AOC and NADPH content of Schizochytrium sp. HS-308 in the presence of orlistat and normal conditions
T-AOC of Schizochytrium sp. under normal fermentation conditions gradually increased during the fermentation process, and reached the maximum at $96 \mathrm{~h}$ (Fig. 4B). Interestingly, the $\mathrm{T}$-AOC of the $5 \mathrm{mg} / \mathrm{L}$ orlistat addition group also gradually increased, but the T-AOC level exceeded the control group at $72 \mathrm{~h}$, and reached the maximum at $120 \mathrm{~h}$. Meanwhile, the T-AOC of the $1000 \mathrm{mg} / \mathrm{L}$ orlistat added group was at a low level from 24 to $96 \mathrm{~h}$, but increased rapidly at $120 \mathrm{~h}$, and almost three times that of the control group. NADPH is an essential reducing power for fatty acid synthesis. It was observed that the NADPH level of the control group was always higher than the orlistat addition group from 24 to $120 \mathrm{~h}$ (Fig. 4C).

\section{Dynamic expression of genes associated with the lipase inhibitor}

During the oscillation, significant changes were detected in the expression of genes in the orlistat treatment groups, particularly, the transcription of genes responding to fatty acid metabolism at $72 \mathrm{~h}$ (Fig. 5). As shown in Fig. 5A, approximately 7900 genes from Schizochytrium sp. were included in the statistical analysis. Regarding DEGs, there were 170 and 145 upregulated genes, and 16 and 13 downregulated genes in the $5 \mathrm{mg} / \mathrm{L}$ and $1000 \mathrm{mg} / \mathrm{L}$ orlistat treatment groups compared with the control, respectively. Orlistat addition induced modulations of 264 significant DEGs, of which 80 showed overlap in the $5 \mathrm{mg} / \mathrm{L}$ and $1000 \mathrm{mg} / \mathrm{L}$ orlistat treatments. In contrast, 106 and 78 DEGs were expressed exclusively in the $5 \mathrm{mg} / \mathrm{L}$ and $1000 \mathrm{mg} / \mathrm{L}$ orlistat treatments, respectively (Fig. 5B), suggesting drastic metabolic reorganization to combat the stress of orlistat addition and enhance the chance of survival.

Under the two orlistat treatments, the average transcriptional level of $\mathrm{ABC}$ transporters that require $\mathrm{ATP}$ consumption increased by 3.85 and 4.35 times, respectively. At the same time, electron carrier activity and oxidoreductase activity-related gene transcription levels were also significantly upregulated (Fig. 5C). In addition, five key genes related to fatty acid synthesis and lipid accumulation (i.e., FAS, $\mathrm{PfaA}, \mathrm{PfaB}, \mathrm{PfaC}$ and DGAT), two key genes related to the accumulation and utilization of acetyl-CoA (i.e., ACC and ACL), two key genes related to NADPH supply (i.e., ME and G6PDH), one key gene involved in glycolysis pathway (i.e., PK), one gene related to TAG hydrolysis (i.e., TAGL), and three key genes related to the oxidative defense system (i.e., SOD, 
CAT and APX) were analyzed by the transcription levels at $72 \mathrm{~h}$. Compared with normal culture, the transcription levels of PK and TAGL genes were significantly upregulated in the orlistat addition group. However, the presence of high concentrations of orlistat inhibited TAGL from functioning, thus leading to the accumulation of lipids. Interestingly, five genes related to fatty acid biosynthesis (FAS, PfaA, PfaB, PfaC and DGAT) and the two main genes produced by NADPH (G6PDH and ME) were no significant change, which also verified that the accumulation of lipids was originated from the inhibitory effect of orlistat on lipase.

\section{Metabolite profiling of Schizochytrium sp. HX-308 with lipase inhibitor}

Compared with the control treatment, glucose consumption increased over time in the $1000 \mathrm{mg} / \mathrm{L}$ orlistat treatment group, and the fructose, mannitol, and xylitol concentrations also increased (Fig. 6). In addition, the galactose and sorbitol concentrations increased. The changes in the fructose, mannitol, and galactose concentrations indicated that the addition of orlistat can accelerate the rate of glucose metabolism and change intracellular glucose metabolism to prevent and deal with the possible external adverse environment. Additionally, glycine concentration converted from 3-phosphoglycerate and alanine converted from pyruvate changed significantly compared with the control. The amino acid content remained high at $48 \mathrm{~h}$ and then declined in the later fermentation stages (Additional file 1: Fig. S5). The TCA cycle is the main source of ATP for lipid accumulation in Schizochytrium sp., and succinic acid is the main metabolite in the TCA cycle. It showed that the succinic acid content in the orlistat treatment groups was higher than that in the control group. The increase in the succinic acid content indicates that the carbon metabolic flow of the TCA cycle was active during the fermentation process, which implied that the addition of orlistat might cause the migration of the metabolic flow, resulting in a large amount of acetyl-CoA entering the TCA cycle to produce more ATP for the growth of Schizochytrium sp. and fatty acid accumulation, which was consistent with the transcriptome analysis. At the same time, the proline and 4-aminobutyric acid concentrations increased compared with the control, especially 4-aminobutyric acid, which was low before $48 \mathrm{~h}$. Upon entering the lipid accumulation period, the concentration of 4-aminobutyric acid increased rapidly. The control reached its peak at $96 \mathrm{~h}$, which was 1.75 times higher than the initial intracellular concentration, while the peak in the $1000 \mathrm{mg} / \mathrm{L}$ orlistat treatment group was earlier (Additional file 1: Fig. S5).

The addition of orlistat reduced the phosphoric acid concentration in the metabolites of Schizochytrium sp., but the concentration of inositol increased significantly. When Schizochytrium sp. entered the period of lipid accumulation, the enhancement of the GABA metabolic pathway could supplement the deficiency of NADH and maintain intracellular reactive oxygen species levels, which is beneficial for lipid accumulation, while proline and myo-inositol played an important biological function for cells to adapt to environmental pressure. During the fermentation process, the phosphoric acid concentration also changed significantly.

In addition, the fermentation conditions of orlistat were tested in Thraustochytrid Aurantiochytrium. Unlike Schizochytrium sp., $5 \mathrm{mg} / \mathrm{L}$ orlistat obviously promoted Aurantiochytrium sp. to accumulate saturated fatty acids, while $1000 \mathrm{mg} / \mathrm{L}$ orlistat had no obvious effect on the fatty acid composition of Aurantiochytrium sp., which might be the different types of lipase in Aurantiochytrium sp. and Schizochytrium sp. (Additional file 1: Figs. S6, S7). After the 120 h fermentation, Aurantiochytrium sp. lipid productivity and GLCR increased by $11.18 \%$ and $4.59 \%$, respectively (Additional file 1: Fig. S8). The result proved that the applicability of orlistat fermentation conditions for the production of microbial lipids by thraustochytrids.

\section{Discussion}

Sterol, squalene and lipids are the main metabolites of Schizochytrium sp. [33], the inhibition of the squalene epoxidation pathway and sterol biosynthesis pathway is theoretically feasible to provide acetyl-CoA for lipid synthesis. The inhibition of PEPC and ICDH activity has a positive effect on lipid accumulation in other lipid-producing microorganisms and may increase lipid accumulation in Schizochytrium sp. Similarly, the degradation and utilization of TAGs by lipase is an obstacle to lipid accumulation, especially in the middle and late stages of fermentation (Fig. 7). Thus, PEPC may convert PEP into

\footnotetext{
(See figure on next page.)

Fig. 5 A Volcano plots showing p-values $(-\log 10)$ vs. feature ratio of $(\log 2), 5 \mathrm{mg} / \mathrm{L}$ vs. Control and $1000 \mathrm{mg} / \mathrm{L}$ vs. Control. B Venn diagram showing the unique and overlapping differentially abundant features in different orlistat concentration. C Functional analysis (including KEGG pathways and GO classes for gene classification) of gene with significantly changed induced by orlistat under $5 \mathrm{mg} / \mathrm{L}$ and $1000 \mathrm{mg} / \mathrm{L}$. D Analysis of the transcription level of key enzyme genes of Schizochytrium in orlistat and normal conditions at $72 \mathrm{~h}$. The three subunits of the PKS gene, include PfaA, PfaB and PfaC; DGAT gene: diacylglycerol acyltransferase gene; SOD gene: superoxide dismutase gene; CAT gene: catalase gene; APX gene: ascorbate peroxidase gene
} 


\section{A}

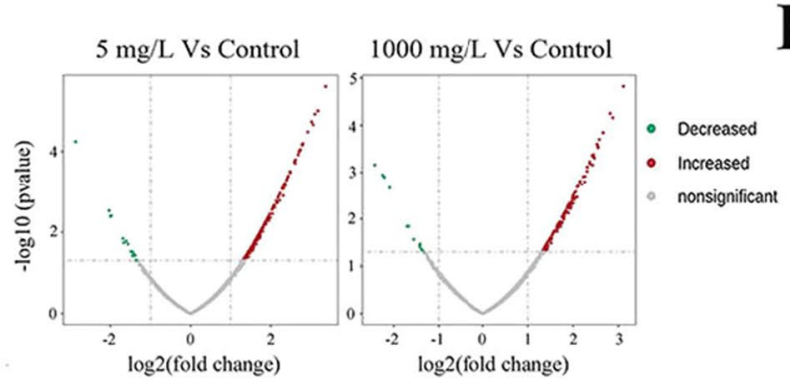

\section{B}

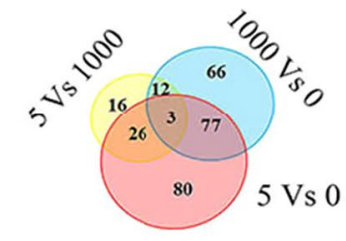

C Number of significant change genes

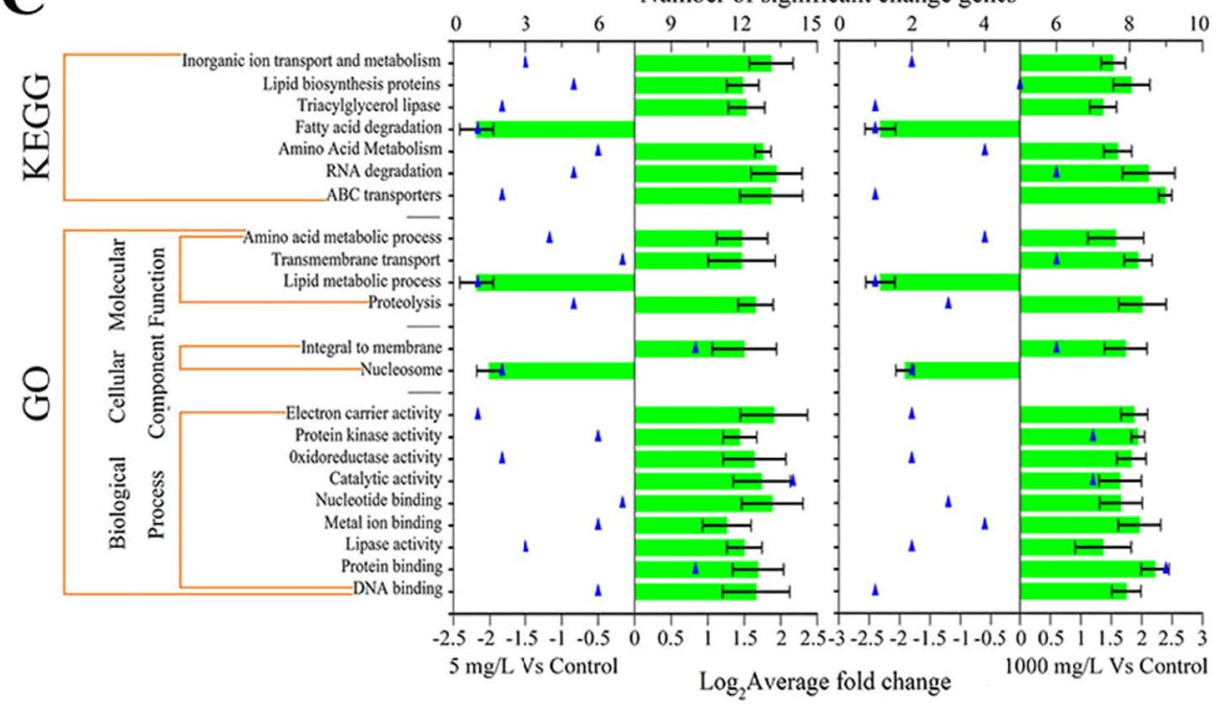

D

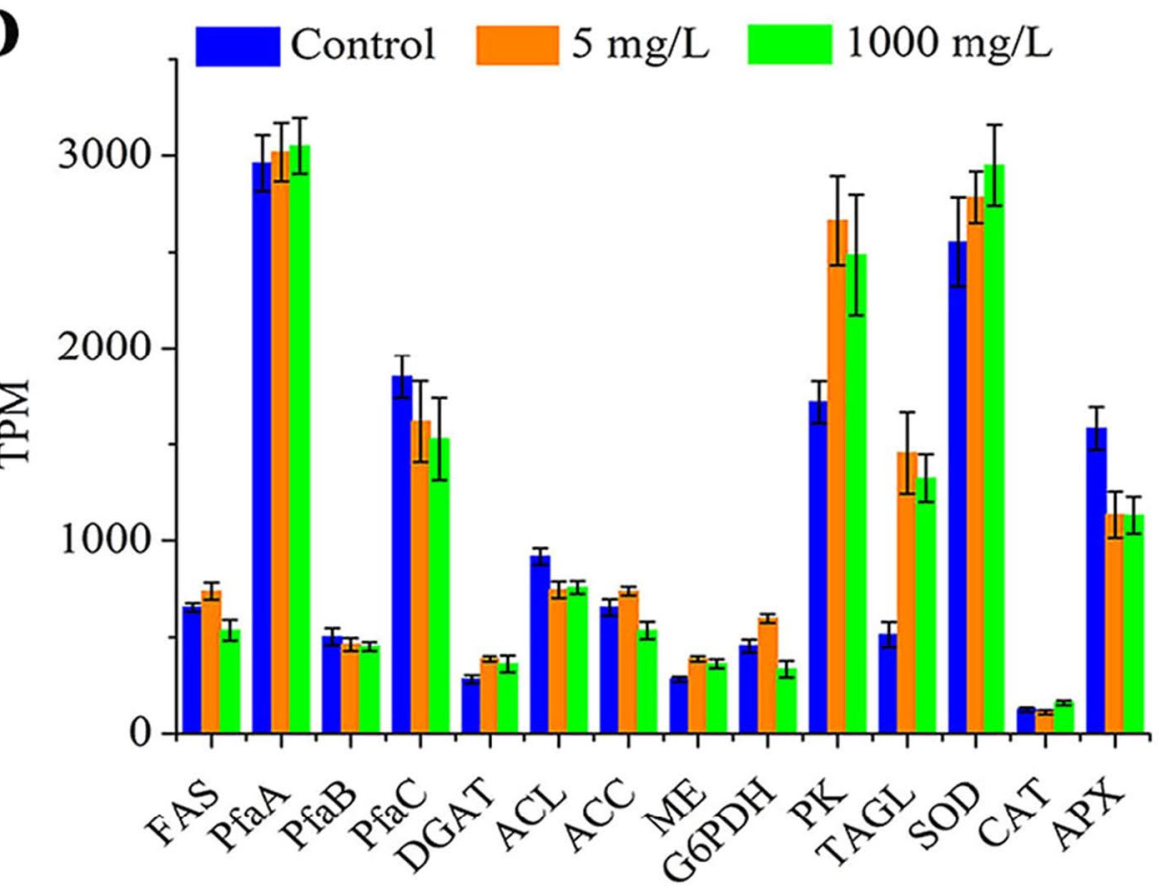

Fig. 5 (See legend on previous page.) 


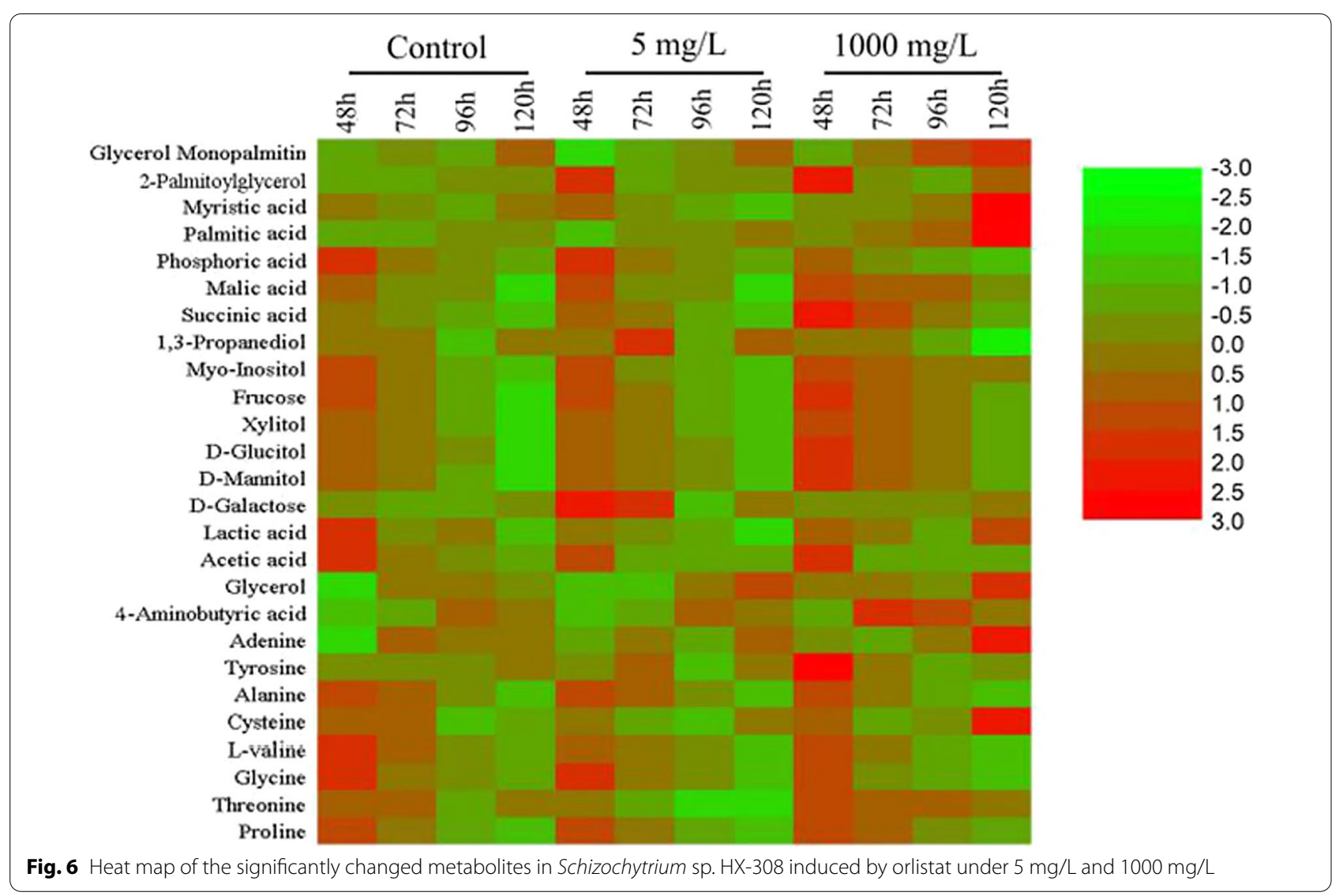

succinic acid, and the accumulation of succinic acid can enhance the supply of ATP. The addition of quinoxaline to inhibit this process was not conducive for the growth of Schizochytrium sp., and inhibition of sterols production also had an adverse effect on lipid accumulation. Lipids are important energy substances, and the use of lipids first requires lipase is required to hydrolyze TAG into free fatty acids, which releases energy through the $\beta$-oxidation pathway [33]. It is well documented that the knockout of lipase can significantly promote the accumulation of lipids in microalgae [19]. Orlistat is a potent lipase inhibitor, which achieves the effect of lipid accumulation by inhibiting the degradation of TAG by lipase [34]. Therefore, the addition of lipase inhibitors may improve the lipid yield and GLCR of Schizochytrium sp.

Orlistat's inhibition of lipase function has caused the ability to use lipids to maintain normal life activities to be greatly damaged, so Schizochytrium sp. strengthens the metabolism of glucose to supplement the loss of ATP and acetyl-CoA caused by the downregulation of fatty acid $\beta$-oxidation pathway. At a concentration of $1000 \mathrm{mg} / \mathrm{L}$ orlistat, the proportion of SFA accounted for $39.71 \%$ of the TFAs. This may be because acetyl-CoA and ATP provided by glucose metabolism are also used to synthesize fatty acids, and the inhibition of TAG lipase function also has a positive effect on the accumulation of SFAs. In addition, compared with the synthesis of PUFAs, SFA synthesis requires less acetyl-CoA through the fatty acid synthase (FAS) pathway, and requiring less ATP to activate acetyl-CoA is another possible reason (Additional file 1: Fig. S9). It is also worth noting that the addition of orlistat improved the GLCR, and this change was gratifying, because glucose is the main substrate cost used in lipid production by Schizochytrium sp. [34]. Zhang et al. found that thraustochytrids transfer the main energy metabolism of terpenoid biosynthesis from carbohydrates to lipid $\beta$-oxidation at $60 \mathrm{~h}$, so the addition of lipase inhibitors inhibits this process and leads to an increase in GLCR [35].

In addition, oxygen-consuming microorganisms can transfer the generated hydrogen and electrons to oxygen through electron transfer and oxidative phosphorylation, so that organic matter is oxidized and decomposed to produce carbon dioxide and water and provide energy for their own growth and metabolism [36]. At the same time, cells will inevitably form various types of ROS through different mechanisms, but the accelerated production of ROS has a toxic effect on cell viability. Therefore, the 


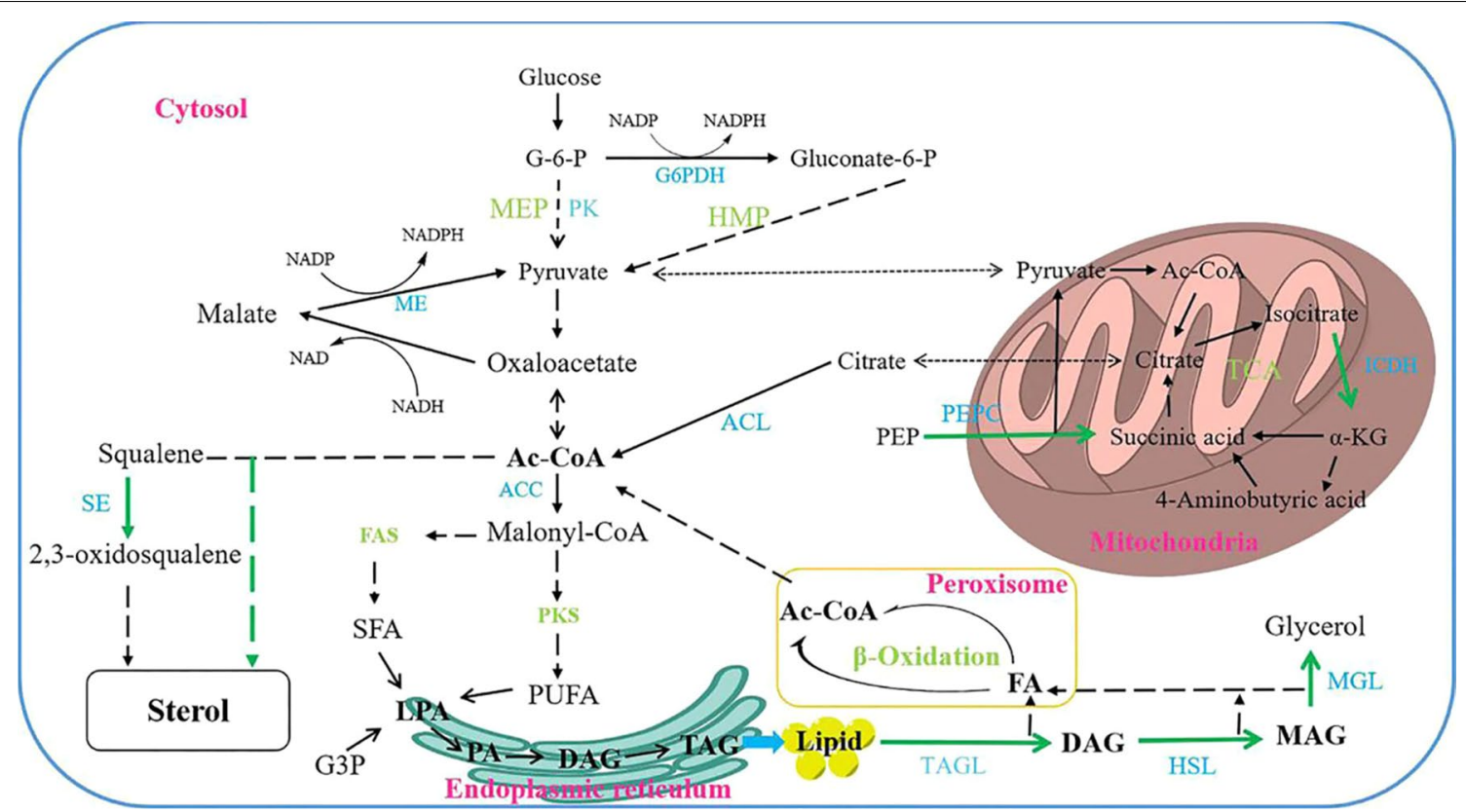

Fig. 7 Schematic map of metabolic pathways on lipid accumulation in Schizochytrium sp. HX-308. The green arrows represent the metabolic pathways of using chemical modulators. G-6-P, glucose-6-phosphoric; G3P, glucose-3-phosphoric; PK, pyruvate kinase; LPA, lysophosphatidic acid; PA, phosphatidic acid; DAG, diacylglycerol; FA, fatty acid; a-KG, a-ketoglutarate; PEP, phosphoenolpyruvate; G6PDH, glucose-6-phosphate; SE, squalene epoxidase; ACC, Acetyl-CoA carboxylase; ACL, ATP-citrate lyase; PEPC, phosphoenolpyruvate carboxylase; ICDH, isocitrate dehydrogenase; TAGL, triacylglycerols lipase; HSL, hormone-sensitive lipase; MGL, monoacylglycerol lipase; ME: malic enzyme; MEP, methylerythritol-phosphate; HMP, Hexose Monophophate Pathway; TCA, tricarboxylic acid cycle

addition of lipase inhibitors promotes the rapid accumulation of lipids and resulting in a rapid depletion of nutrients, therefore, leads to a large increase in ROS [25]. Microorganisms develop a series of mechanisms to remove ROS, such as various antioxidants and antioxidant enzyme systems, to reduce the toxic effects of ROS on cells, which can be evaluated by T-AOC. However, the T-AOC level of the orlistat supplementation group gradually exceeded the control group only in the late fermentation period, which may be the temporary failure of the T-AOC system due to the high ROS level in the early fermentation period. In general, reducing power is necessary for cell growth and metabolism. The addition of orlistat inhibits lipid degradation, but the enhanced glycolysis pathway provides more acetyl-CoA to enter the fatty acid synthesis pathway, thus leading to excessive consumption of NADPH.

Consistent with our previous speculation, the ATP gap caused by the downregulation of the fatty acid $\beta$-oxidation pathway is supplemented by other metabolic pathways, but the fatty acid synthesis pathway still consumes a large amount of ATP. The increase in the transcription level of the $\mathrm{ABC}$ transporter indirectly confirmed the increase in ATP synthesis [37]. The upregulation of genes related to electron carrier activity and oxidoreductase activity is not only conducive to the supply of NADPH, but also is conducive to the accumulation of lipids by improving the antioxidant capacity of Schizochytrium sp. [29]. The increase in PK gene transcription level means that Schizochytrium sp. uses more glucose, which provides more ATP and acetyl-CoA for fatty acid synthesis; while the increase in TAGL gene transcription level means that more lipases that hydrolyze TAG are produced, which is unfavorable for lipid accumulation [38]. This conclusion can also be confirmed by the downregulation of gene expression levels related to Fatty acid degradation pathway. Microorganisms have a complete antioxidant enzyme system to remove active oxygen generated by life activities. These systems are mainly composed of SOD, CAT and APX [39]. Among them, SOD can catalyze the disproportionation of extremely toxic superoxide anions into oxygen and hydrogen peroxide [40]. Then, under the catalysis of CAT or APX, hydrogen peroxide is removed to generate $\mathrm{H}_{2} \mathrm{O}$ and $\mathrm{O}_{2}$. Therefore, the SOD gene showed a higher transcription level due to the high level of ROS accumulation in the orlistat addition group.

The carbon source is the basic substance used by microorganisms to maintain cell growth and survival. Glucose, the most common carbon source, is a key 
component of Schizochytrium sp. metabolism. The high consumption of glucose caused by the addition of orlistat not only accumulates lipids, but also intensifies the flow of intracellular glucose metabolism to other metabolic pathways. Glucose meets the needs of cell growth but is also involved in the synthesis of polysaccharides and their derivatives. Amino acids are necessary for the metabolism of carbon and nitrogen, and are important precursors for the synthesis of proteins, nucleotides, and other cellular components [41]. They play important roles in the regulation of cell growth and metabolism, and maintaining cell physiological functions. Phosphoric acid is an important component of the phospholipid bilayer of cell membranes and organelle membranes, while myoinositol has a variety of physiological functions; it not only stores carbohydrates and NADPH, but also acts as a coenzyme regulator [42]. 4-aminobutyric acid is the core substance of the $\gamma$-aminobutyric acid (GABA) metabolic pathway and cannot be ignored. The GABA metabolic pathway is a pathway that produces NADH energy [22, 43]. Ren et al. had reported that under phosphorus-limited conditions, ME and G6PDH maintain high activity levels and provide a large amount of NADPH [44]. Therefore, the reduction of phosphoric acid may also increase the activity of certain enzymes in Schizochytrium sp. thus promote the accumulation of fatty acids.

\section{Conclusion}

The green synthesis of lipids through microbial fermentation is attractive, but it is difficult to carry out because of its high costs and low productivity. In this study, we added $1000 \mathrm{mg} / \mathrm{L}$ lipase inhibitor before the start of fermentation to obtain a lipid yield of $87.89 \mathrm{~g} / \mathrm{L}$, which was $34.39 \%$ higher than that of the control, while the GLCR, PUFA and SFA yield were increased 9.45\%, 64.52\% and $24.04 \%$, respectively. And orlistat fermentation conditions also have been successful in Thraustochytrid Aurantiochytrium. The transcription and metabolomics analysis showed that the inhibition of the TAG degradation pathway and the enhancement of energy supply are key to increasing the lipid accumulation. In the presence of lipase inhibitors, the DEGs related to the fatty acid degradation pathway in Schizochytrium sp. were significantly downregulated, and the demand for glucose was significantly increased. From the perspective of industrial development, our work is competitive, because it is a simple, effective approach to increase lipid productivity and GLCR at the same time. Additionally, our work offers an insight into the production of other microbial lipids and the design of an engineered Schizochytrium sp. with higher lipid productivity by genetic engineering in the future.

\section{Materials and methods}

\section{Chemicals and screening standard}

Quinoxalin and hexaconazole were purchased from Aladdin (Shanghai, China), and terbinafine hydrochloride, vorasidenib, and orlistat were purchased from Macklin (Shanghai, China). These chemicals were of analytical purity and were dissolved in ethanol. Adonitol, Methoxyamine hydrochloride and pyridine were purchased from Macklin (Shanghai, China), and N-methyl-N(trimethylsilyl) trifluoroacetamide was purchased from Sigma (Burlington, USA). All samples were prepared in glass vials and stored at $4{ }^{\circ} \mathrm{C}$. Quinoxalin $(10 \mathrm{mg} / \mathrm{L})$, hexaconazole $(10 \mathrm{mg} / \mathrm{L})$, terbinafine $(10 \mathrm{mg} / \mathrm{L})$, vorasidenib $(0.1 \mathrm{mg} / \mathrm{L})$, and orlistat $(10 \mathrm{mg} / \mathrm{L})$ were added to the fermentation medium at the beginning of fermentation.

The lipid yield, GLCR and fatty acids content were used as indicators to evaluate their performance. The GLCR was determined as follows:

$$
\mathrm{GLCR}=\frac{\text { Total lipid production }}{\text { Total glucose usage }}(\mathrm{wt} / \mathrm{wt} \%) .
$$

\section{Microorganism and culture conditions}

Schizochytrium sp. HX-308 (CCTCC M 209059) was isolated from seawater and stored in the China Center for Type Culture Collection. The strain was preserved in $20 \%(\mathrm{v} / \mathrm{v})$ glycerol at $-80{ }^{\circ} \mathrm{C}$. The seed culture medium and culture conditions were the same as those used in a previous study [45]. The seeds of Schizochytrium sp. cells were cultured for three passages and then transferred to $500 \mathrm{ml}$ shake flasks containing $100 \mathrm{~mL}$ of the medium at a final concentration of $10 \%$ for the batch culture. Finally, Schizochytrium sp. was maintained in artificial seawater with $100 \mathrm{~g} / \mathrm{L}$ glucose and $5 \mathrm{~g} / \mathrm{L}$ yeast extract at $28{ }^{\circ} \mathrm{C}$ under constant orbital shaking at $170 \mathrm{rpm}$.

The artificial seawater contained: $20 \mathrm{~g} / \mathrm{L}$ monosodium glutamate, $10 \mathrm{~g} / \mathrm{L} \mathrm{Na}_{2} \mathrm{SO}_{4}, 4.8 \mathrm{~g} / \mathrm{L} \mathrm{KH}_{2} \mathrm{PO}_{4}, 4.8 \mathrm{~g} / \mathrm{L}$ $\mathrm{MgSO}_{4} \cdot 7 \mathrm{H}_{2} \mathrm{O}, 2.8 \mathrm{~g} / \mathrm{L}(\mathrm{NH} 4)_{2} \mathrm{SO}, 1 \mathrm{~g} / \mathrm{L} \mathrm{KCl}$, and $0.2 \mathrm{~g} / \mathrm{L}$ $\mathrm{CaCl}_{2}$. The trace element solution contained $6 \mathrm{mg} / \mathrm{L}$ $\mathrm{Na}_{2}$ EDTA, $8 \mathrm{mg} / \mathrm{L} \quad \mathrm{MnCl}_{2} \cdot 4 \mathrm{H}_{2} \mathrm{O}, 0.8 \mathrm{mg} / \mathrm{L} \quad \mathrm{ZnSO}_{4}$, $0.29 \mathrm{mg} / \mathrm{L} \mathrm{FeSO}, 0.01 \mathrm{mg} / \mathrm{L} \mathrm{CoCl}{ }_{2} \cdot 6 \mathrm{H}_{2} \mathrm{O}, 0.6 \mathrm{mg} / \mathrm{L}$ $\mathrm{CuSO}_{4} \cdot 5 \mathrm{H}_{2} \mathrm{O}, 0.06 \mathrm{mg} / \mathrm{L} \mathrm{NiSO} \cdot 6 \mathrm{H}_{2} \mathrm{O}$, and $0.1 \mathrm{mg} / \mathrm{L}$ $\mathrm{Na}_{2} \mathrm{MoO}_{4} \cdot 2 \mathrm{H}_{2} \mathrm{O}$. In addition, a vitamin $\mathrm{B}$ mixture $(20 \mathrm{mg} / \mathrm{L})$ was also added to the fermentation medium.

\section{Cell dry weight, total lipids, and fatty acid methyl ester analysis}

The cell dry weight (CDW) was determined gravimetrically by filtering $10 \mathrm{~mL}$ of the samples using a centrifuge for $5 \mathrm{~min}$ at $6500 \mathrm{~g}$. The sample was dried for $48 \mathrm{~h}$ at $60^{\circ} \mathrm{C}$ by transferring the cells to dried and weighed filter paper. During the drying process, the weight was recorded 
repeatedly until the mass remained stable. The fermentation broth $(50 \mathrm{~mL})$ was first high-temperature $\left(50{ }^{\circ} \mathrm{C}\right)$ enzymatic hydrolysis to break the wall of the Schizochytrium sp. HX-308 cells, inactivate the wall-breaking enzyme with ethanol, and perform rotary steaming after extraction with $\mathrm{n}$-hexane $\left(45-50{ }^{\circ} \mathrm{C}\right)$ to get lipids. Finally, the total lipids were calculated by weighing.

Fatty acid methyl esters were prepared by adding $2 \mathrm{~mL}$ of $1 \mathrm{M}$ potassium hydroxide-methanol to a glass tube containing $0.2 \mathrm{~g}$ of dried cells. The glass tube was heated in a $60{ }^{\circ} \mathrm{C}$ water bath for $30 \mathrm{~min}$ and then cooled to room temperature. At this time, $2 \mathrm{~mL}$ of boron trifluoride ether (boron trifluoride:ether $=3: 7, \mathrm{v} / \mathrm{v}$ ) was added and the solution mixed, and then it was placed in a $60{ }^{\circ} \mathrm{C}$ water bath and heated again for $10 \mathrm{~min}$. When the tube was cooled to room temperature, $2 \mathrm{~mL}$ of saturated sodium chloride aqueous solution was added, mixed well, and then $3 \mathrm{~mL}$ of $\mathrm{n}$-hexane was added, mixed well, and allowed to stand until the layers separated. The upper n-hexane phase was taken through the membrane and gas chromatography (GC) detection (GC-2030, Shimadzu, Japan); the GC-related settings and procedures are as described above [24]. All tests were conducted in triplicate, and the results were expressed as the mean \pm standard deviation.

\section{Evaluation of anti-oxidation ability}

The relative ROS content of the samples were evaluated by the fluorescent probe $2^{\prime}, 7^{\prime}$-dichlorodihydrofluorescein diacetate (DCFH-DA) [46]. DCFH-DA fluorescent probe was dissolved in dimethyl sulfoxide to $1 \mathrm{mM}$, and store it at $-20{ }^{\circ} \mathrm{C}$ for later use, then added to the cell culture in a 1:100 ratio, and incubated at $30{ }^{\circ} \mathrm{C}, 170 \mathrm{rpm}$ and dark for $20 \mathrm{~min}$, so that the fluorescent probe can fully enter the cell. The cell samples were washed twice with PBS buffer to sufficiently remove extracellular DCFH-DA, and then dissolve the cell sample in PBS. Finally, the relative content of intracellular ROS was measured by multifunctional microplate reader (Gene Company Limited, China) with excitation at $488 \mathrm{~nm}$ and emission at $525 \mathrm{~nm}$. The T-AOC of Schizochytrium sp. was determined by Micro Total Antioxidant Capacity Assay Kit (Solarbio, China) according to the manufacturer's instructions. NADPH content was determined using the NADP/NADPH Quantification Kit (Beyotime, China) following the instruction of the manufacturer.

One standard unit (STU) is defined as the result produced by the reaction of $1 \mathrm{~mL}$ of $\mathrm{OD}_{600}=1$ bacterial liquid.

\section{Transcriptomic analysis}

High-resolution genome-wide transcription analysis was performed using RNA-Seq at Hangzhou Kaitai
Biotechnology Co., Ltd (Hangzhou, Zhejiang, China). Raw reads were filtered to remove adapters and lowquality reads, and the remaining reads were mapped to the reference genome, Schizochytrium sp. HX-308, for transcript information. Gene expression was normalized by transcripts per kilobase per million mapped reads (TPM), and the number of transcripts per kilobase per million mapped reads was calculated as follows:

$$
\mathrm{TPM}_{i}=\frac{N_{i}}{L_{i}} \cdot\left(\frac{1}{\sum_{j} \frac{N_{j}}{L_{j}}}\right) \cdot 10^{6},
$$

where $N_{\mathrm{i}}$ is the number of reads mapped to the target gene, $L_{\mathrm{i}}$ is the total length of the exons of the target gene, $N_{\mathrm{j}}$ is the number of reads mapped to any gene in the sample, and $L_{\mathrm{j}}$ is the sum of the lengths of the exons of any gene in the sample.

Differentially expressed genes (DEGs) were defined as follows: the sum of mapping reads $\geq 10$ in the two samples, satisfying $\mid \log _{2}$ (fold change) $\mid>1$; a false discovery rate (FDR) correction was performed on the $p$-value to obtain the q-value, and at the same time must satisfy the $p$-value $\leq 0.05$ and $q$-value $\leq 0.05$.

\section{Derivatization and gas chromatography-mass spectrometry analysis}

To investigate the mechanism by which orlistat increased lipid production by Schizochytrium sp. HX-308, a gas chromatography-mass spectrometry (GC-MS) method combined with multivariate analyses was used to determine the changes in metabolites in the presence of different concentrations of orlistat. The sample derivatization process was in accordance with a previously reported method [15], with some modifications. The above sample was mixed with $25 \mu \mathrm{L}$ of an internal standard (Adonitol, $0.2 \mathrm{mg} / \mathrm{mL}$ ) and dried with a nitrogen blower. Methoxyamine hydrochloride $(40 \mu \mathrm{l})$ in pyridine $(20 \mathrm{mg} / \mathrm{mL})$ was added to the dried sample and incubated at $40{ }^{\circ} \mathrm{C}$ for $1 \mathrm{~h}$. Then, the sample was silylated for $2 \mathrm{~h}$ at $30^{\circ} \mathrm{C}$ by adding $60 \mu \mathrm{l}$ of $\mathrm{N}$-methyl$\mathrm{N}$-(trimethylsilyl) trifluoroacetamide and vortex mixing for $60 \mathrm{~s}$.

The GC-MS system included a GC (GC-2030, Shimadzu, Japan) with a DB-5MS capillary column (parameter: $60 \mathrm{~m} \times 0.25 \mathrm{~mm} \times 0.25 \mu \mathrm{m}$, Agilent, USA) and mass spectrometer (GCMS-QP2020 NX, Shimadzu, Japan). Ionization was performed using an electrospray ionization source operating in either the positive or negative ionization mode, and helium was used for collision-induced dissociation at a flow rate of 
$1 \mathrm{~mL} / \mathrm{min}$ (constant flow). The GC temperature programming was set at $70{ }^{\circ} \mathrm{C}$ for $2 \mathrm{~min}$, then increased to $300{ }^{\circ} \mathrm{C}$ in increments of $5{ }^{\circ} \mathrm{C} / \mathrm{min}$ and held for $3 \mathrm{~min}$. The temperatures of the injection, transfer line, and ion source were 250,280 , and $230{ }^{\circ} \mathrm{C}$, respectively. The mass scan range was $50-800 \mathrm{~m} / \mathrm{z}$.

\begin{abstract}
Abbreviations
ACC: Acetyl-CoA carboxylase; ACP: Acyl carrier protein; AT: Acyltransferase; ATP: Adenosine triphosphate; APX: Ascorbate peroxidase; ACL: ATP-citrate lyase; CAT: Catalase; CDW: Cell dry weight; Cys: Cysteine; DHA: Docosahexaenoic acid; DPA: Docosapentaenoic acid; DH: Dehydratase; DAG: Diacylglycerol; DGAT: Diacylglycerol acyltransferase; DCFH-DA: 2',7'-Dichlorodihydrofluorescein diacetate; ER: Enoylreductase; EPA: Eicosapentaenoic acid; FA: Fatty acid; FAS: Fatty acid synthase; GC: Gas chromatography; GC-MS: Gas chromatography-mass spectrometry; GLCR: Glucose-to-lipid conversion rate; G3P: Glucose3-phosphoric; G-6-P: Glucose-6-phosphoric; G6PDH: Glucose-6-phosphate; HMP: Hexose Monophophate Pathway; HSL: Hormone-sensitive lipase; ICDH: Isocitrate dehydrogenase; a-KG: a-Ketoglutarate; KR: Ketoreductase; KS: Ketosynthase; LPA: Lysophosphatidic acid; ME: Malic enzyme; MEP: Methylerythritol-phosphate; MGL: Monoacylglycerol lipase; NADPH: Nicotinamide adenine dinucleotide; PA: Phosphatidic acid; PEPC: Phosphoenolpyruvate carboxylase; PEP: Phosphoenolpyruvate; PKS: Polyketide synthase; PUFAs: Polyunsaturated fatty acids; PK: Pyruvate kinase; ROS: Reactive oxygen species; SFAs: Saturated fatty acids; SE: Squalene epoxidase; SOD: Superoxide dismutase; T-AOC: Total antioxidant capacity; TFAs: Total fatty acids; TPM: Transcripts per kilobase per million mapped reads; TAG: Triacylglycerol; TAGL: Triacylglycerols lipase; TCA: Tricarboxylic acid cycle.
\end{abstract}

\section{Supplementary Information}

The online version contains supplementary material available at https://doi. org/10.1186/s13068-021-02097-4.

Additional file 1. Additional figures and table.

\section{Acknowledgements}

This work was supported by the Nature Science Foundation of Jiangsu Province (No. BK20190706), the National Natural Science Foundation of China (No. 21908112, No. 22038007).

\section{Authors' contributions}

WM and YZW planned the experiments. WM, YZW, FTN, FD, YSX, PWH, XMS, and $\mathrm{HH}$ performed the experiments. WM, YZW, and YSX analyzed the data. WM, FTN, and PWH wrote the paper. All authors read and approved the final manuscript.

\section{Availability of data and materials}

All data generated or analysed during this study are included in this published article and its additional information files.

\section{Declarations}

Ethics approval and consent to participate

The authors declare that this study does not involve human subjects, human material and human data.

\section{Competing interests}

The authors declare that they have no competing interests.

Received: 17 November 2021 Accepted: 18 December 2021

Published online: 31 December 2021

\section{References}

1. Morabito C, Bournaud C, Maës C, Schuler M, Rébeillé F. The lipid metabolism in thraustochytrids. Prog Lipid Res. 2019;76:101007.

2. Weill P, PlissoNn Eau C, Legrand P, Rioux V, Thibault R. May omega-3 fatty acid dietary supplementation help reduce severe complications in Covid19 patients? Biochimie. 2020;179:275-80.

3. Sohedein M, Wan WM, Ilham Z, Babadi AA, Siew-Moi P. Vital parameters for biomass, lipid, and carotenoid production of thraustochytrids. J Appl Phycol. 2020:32(1):1-14.

4. Patel A, Karageorgou D, Rova E, Katapodis P, Matsakas L. An overview of potential oleaginous microorganisms and their role in biodiesel and omega-3 fatty acid-based industries. Microorganisms. 2020;8(3):434.

5. Nerantzis ME. Microalgae for high-value compounds and biofuels production: a review with focus on cultivation under stress conditions. Biotechnol Adv. 2013;31(8):1532-42.

6. Chen B, Wan C, Mehmood MA, Chang JS, Bai F, Zhao X. Manipulating environmental stresses and stress tolerance of microalgae for enhanced production of lipids and value-added products - a review. Bioresour Technol. 2017;244:1198-206.

7. Jakobsen AN, Aasen IM, Josefsen KD, Strm AR. Accumulation of docosahexaenoic acid-rich lipid in thraustochytrid Aurantiochytrium sp. strain T66: effects of N and P starvation and $\mathrm{O} 2$ limitation. Appl Microbiol Biotechnol. 2008;80(2):297-306.

8. Huang TY, Lu WC, Chu IM. A fermentation strategy for producing docosahexaenoic acid in Aurantiochytrium limacinum SR21 and increasing C22:6 proportions in total fatty acid. Bioresour Technol. 2012;123:8-14.

9. Yin FW, Zhang YT, Jiang JY, Guo DS, Gao S, Gao Z. Efficient docosahexaenoic acid production by Schizochytrium sp. via a two-phase pH control strategy using ammonia and citric acid as $\mathrm{pH}$ regulators. Process Biochem. 2019;77:1-7.

10. Kaye Y, Grundman O, Leu S, Zarka A, Zorin B, Didi-Cohen S, KhozinGoldberg I, Boussiba S. Metabolic engineering toward enhanced LC-PUFA biosynthesis in Nannochloropsis oceanica: overexpression of endogenous $\Delta 12$ desaturase driven by stress-inducible promoter leads to enhanced deposition of polyunsaturated fatty acids in TAG. Algal Res. 2015;11:387-98.

11. Suen YL, Tang HM, Huang JC, Chen F. Enhanced production of fatty acids and astaxanthin in Aurantiochytrium sp. by the expression of vitreoscilla hemoglobin. J Agric Food Chem. 2014;62:12392-8.

12. Wang S, Lan C, Wang Z, Wan W, Song X. Optimizing eicosapentaenoic acid production by grafting a heterologous polyketide synthase pathway in the thraustochytrid Aurantiochytrium. J Agric Food Chem. 2020;68:11253-60.

13. Du F, Wang YZ, Xu YS, Shi TQ, Huang H. Biotechnological production of lipid and terpenoid from thraustochytrids. Biotechnol Adv. 2021;48(8):107725.

14. Garlick JM, Sturlis SM, Bruno PA, Yates JA, Mapp AK. Norstictic acid is a selective allosteric transcriptional regulator. J Am Chem Soc. 2021;143:9297-302.

15. Li Z, Ling X, Zhou H, Meng T, Zeng J, Hang W, Shi Y, He N. Screening chemical modulators of benzoic acid derivatives to improve lipid accumulation in Schizochytrium limacinum SR21 with metabolomics analysis. Biotechnol Biofuels. 2019:12:209.

16. Ratledge $C$. Fatty acid biosynthesis in microorganisms being used for single cell oil production. Biochimie. 2004;86(11):807-15.

17. Cheng Jh, Niu Y, Lu S, Yuan YI. Metabolome analysis reveals ethanolamine as potential marker for improving lipid accumulation of model photosynthetic organisms. J Chem Technol Biotechnol. 2012;87(10):1409-18.

18 Liu ZX, You S, Tang BP, Wang B, Sheng S, Wu FA, Wang J. Inositol as a new enhancer for improving lipid production and accumulation in Schizochytrium sp. SR21. Environ Sci Pollut Res. 2019;26:35497-508.

19. Trentacoste EM, Shrestha RP, Smith SR, Glé C, Gerwick WH. Metabolic engineering of lipid catabolism increases microalgal lipid accumulation without compromising growth. Proc Natl Acad Sci USA. 2013;110:19748-53.

20. Yazawa H, Kumagai $H$, Uemura H. Characterization of triglyceride lipase genes of fission yeast Schizosaccharomyces pombe. Appl Microbiol Biotechnol. 2012;96(4):981-91. 
21. Zan X, Cui F, Sun J, Zhou S, Song Y. Novel dual-functional enzyme Lip10 catalyzes lipase and acyltransferase activities in the oleaginous fungus Mucor circinelloides. J Agric Food Chem. 2019;67:13176-84.

22. Li Q, Zhao Y, Ding W, Han B, Yu X. Gamma-aminobutyric acid facilitates the simultaneous production of biomass, astaxanthin and lipids in Haematococcus pluvialis under salinity and high-light stress conditions. Bioresour Technol. 2020;320:124418.

23. Chang M, Zhang T, Li L, Lou F, Wang X. Choreography of multiple omics reveals the mechanism of lipid turnover in Schizochytrium sp. S31. Algal Res. 2021;54:102182.

24. Sun XM, Ren LJ, Ji XJ, Chen SL, Huang H. Adaptive evolution of Schizochytrium sp. by continuous high oxygen stimulations to enhance docosahexaenoic acid synthesis. Bioresour Technol. 2016;211:374-81.

25. Sun XM, Ren LJ, Bi ZQ, Ji XJ, Zhao QY, He H. Adaptive evolution of microalgae Schizochytrium sp. under high salinity stress to alleviate oxidative damage and improve lipid biosynthesis. Bioresour Technol. 2018;267:438-44.

26. Chandrasekaran K, Dhanraj M, Chadha A. Effects of organic and inorganic salts on docosahexaenoic acid (DHA) production by a locally isolated strain of Thraustochytrium sp. T01. Prep Biochem Biotechnol. 2018;48(7):1-6.

27. Nazir Y, Halim H, Prabhakaran P, Ren X, Naz T, Mohamed H, Nosheen S, Mustafa K, Yang W, Hamid AA. Different classes of phytohormones act synergistically to enhance the growth, lipid and DHA biosynthetic capacity of Aurantiochytrium sp. SW1. Biomolecules. 2020;10(5):755.

28. Zhao B, Li Y, Li C, Yang H, Wang W. Enhancement of Schizochytrium DHA synthesis by plasma mutagenesis aided with malonic acid and zeocin screening. Appl Microbiol Biotechnol. 2018;102:2351-61.

29. Ren $\sqcup$, Sun XM, Ji XJ, Chen SL, Guo DS, Huang H. Enhancement of docosahexaenoic acid synthesis by manipulation of antioxidant capacity and prevention of oxidative damage in Schizochytrium sp. Bioresour Technol. 2017;223:141-8

30. Cui GZ, Ma Z, Liu YJ, Feng Y, Sun Z, Cheng Y, Song X, Cui Q. Overexpression of glucose-6-phosphate dehydrogenase enhanced the polyunsaturated fatty acid composition of Aurantiochytrium sp. SD116. Algal Res. 2016;19:138-45.

31 Han X, Zhao Z, Wen Y, Chen Z. Enhancement of docosahexaenoic acid production by overexpression of ATP-citrate lyase and acetyl-CoA carboxylase in Schizochytrium sp. Biotechnol Biofuels. 2020;13(1):1-13.

32. Yan J, Cheng R, Lin X, You S, Ma Y. Overexpression of acetyl-CoA synthetase increased the biomass and fatty acid proportion in microalga Schizochytrium. Appl Microbiol Biotechnol. 2012;97(5):1933-9.

33 Quilodrán B, Hinzpeter I, Hormazabal E, Quiroz A, Shene C. Docosahexaenoic acid (C22:6n-3, DHA) and astaxanthin production by Thraustochytriidae sp. AS4-A1 a native strain with high similitude to Ulkenia sp.: evaluation of liquid residues from food industry as nutrient sources. Enzyme Microb Technol. 2010;47(1-2):24-30.

34. Franz AK, Danielewicz MA, Wong DM, Anderson LA, Boothe JR. Phenotypic screening with oleaginous microalgae reveals modulators of lipid productivity. ACS Chem Biol. 2013;8:1053-62.

35. Zhang A, Mernitz K, Wu C, Xiong W, Wang X. ATP drives efficient terpene biosynthesis in marine Thraustochytrids. MBio. 2021;12(3):e0088121.

36. Lushchak VI. Adaptive response to oxidative stress: bacteria, fungi, plants and animals. Comp Biochem Physiol C Toxicol Pharmacol. 2011;153(2):175-90.

37. Wang Z, Cheng J, Zhang X, Chen L, Liu J. Metabolic pathways of Chlorella sp. cells induced by exogenous spermidine against nitric oxide damage from coal-fired flue gas. Bioresour Technol. 2021;328(38):124827.

38. Yue XH, Chen WC, Wang ZM, Liu PY, Wan X. Lipid distribution pattern and transcriptomic insights revealed the potential mechanism of docosahexaenoic acid traffics in Schizochytrium sp. A-2. J Agric Food Chem. 2019;67(34):9683-93.

39. Chokshi K, Pancha I, Ghosh A, Mishra S. Nitrogen starvation-induced cellular crosstalk of ROS-scavenging antioxidants and phytohormone enhanced the biofuel potential of green microalga Acutodesmus dimorphus. Biotechnol Biofuels. 2017;10(1):60.

40. Tsang CK, Chen M, Cheng X, Qi Y, Chen Y, Das I, Li X, Vallat B, Fu LW, Qian CN. SOD1 phosphorylation by mTORC1 couples nutrient sensing and redox regulation. Mol Cell. 2018;70(3):502-15.
41. Li J, Ren LJ, Sun GN, Qu L, Huang H. Comparative metabolomics analysis of docosahexaenoic acid fermentation processes by Schizochytrium sp. under different oxygen availability conditions. OMICS. 2013;17(5):269-81.

42. Siniossoglou S. Phospholipid metabolism and nuclear function: roles of the lipin family of phosphatidic acid phosphatases. Biochim Biophys Acta. 2013;1831(3):575-81.

43. Poonam S, Abhishek G, Sheena K, Ismail R, Faizal B. Combined metals and EDTA control: an integrated and scalable lipid enhancement strategy to alleviate biomass constraints in microalgae under nitrogen limited conditions. Energy Convers Manag. 2016;114:100-9.

44. Ren LJ, Yun F, Li J, Liang Q, He H. Impact of phosphate concentration on docosahexaenoic acid production and related enzyme activities in fermentation of Schizochytrium sp. Bioprocess Biosyst Eng. 2013;36(9):1177-83.

45. Qu L, Ji XJ, Ren LJ, Nie ZK, Feng Y, Wu WJ, Ouyang PK, Huang H. Enhancement of docosahexaenoic acid production by Schizochytrium sp. using a two-stage oxygen supply control strategy based on oxygen transfer coefficient. Lett Appl Microbiol. 2015;52(1):22-7.

46. Liu YH, Alimujiang A, Wang X, Luo SW, Li HY. Ethanol induced jasmonate pathway promotes astaxanthin hyperaccumulation in Haematococcus pluvialis. Bioresour Technol. 2019;289:121720.

\section{Publisher's Note}

Springer Nature remains neutral with regard to jurisdictional claims in published maps and institutional affiliations.
Ready to submit your research? Choose BMC and benefit from:

- fast, convenient online submission

- thorough peer review by experienced researchers in your field

- rapid publication on acceptance

- support for research data, including large and complex data types

- gold Open Access which fosters wider collaboration and increased citations

- maximum visibility for your research: over 100M website views per year

At BMC, research is always in progress.

Learn more biomedcentral.com/submissions 